\title{
The effect of pressurization path on high pressure gas forming of Ti-3Al-2.5V at elevated temperature
}

\author{
Gang Liu ${ }^{1,2, a}$, Jianlong Wang ${ }^{1}$, Kexin Dang ${ }^{1}$, and Shijian Yuan ${ }^{1,2}$ \\ ${ }^{1}$ School of Materials Science and Engineering, Harbin Institute of Technology, Harbin 150001, China \\ ${ }^{2}$ National Key Laboratory for Precision Hot Processing of Metals, Harbin Institute of Technology, \\ Harbin 150001, China
}

\begin{abstract}
High pressure gas forming is a tubular component forming technology with pressurized gas at elevated temperature, based on QPF, HMGF and Hydroforming. This process can be used to form tube blank at lower temperatures with high energy efficiency and also at higher strain rates. With Ti-3Al-2.5V Ti-alloy tube, the potential of HPGF was studied further through experiments at the elevated temperatures of $650{ }^{\circ} \mathrm{C}$ and $700{ }^{\circ} \mathrm{C}$. In order to know the formability of the Ti-alloy tube, tensile tests were also carried out. The results show that: at the temperatures of $650{ }^{\circ} \mathrm{C}$ and $700^{\circ} \mathrm{C}$, the flow curves exhibit the power-law constitutive relation until peak stress is reached and the deformability is suitable for the HPGF process of Ti-3Al-2.5V alloy tube. The effects of pressurization path on the corner filling process and thickness profile are obvious. The high pressure inflow process can result in temperature difference between the straight wall area and corner area, which makes the thickness profile special. Besides, with the stepped pressurization path, the more constant filling rate and better thickness profile can be obtained.
\end{abstract}

\section{Introduction}

Due to the low density, good strength-to-weight ratio, excellent corrosion resistance and good mechanical properties, titanium and its alloys have become very important commercially over the past fifty years [1]. But titanium alloys are often considered more difficult to form than other metallic alloys such as steel and aluminum because of their high yield stress and low elastic modulus. The hexagonal crystal structure of the $\alpha$-phase also possesses anisotropic characteristics that affect its elastic properties [2]. In order to find a solution to counter the disadvantages mentioned above, the use of elevated temperatures as a process parameter in forming operations represents a potential solution approach. Chen et al. performed V-bend tests and cup drawing tests to examine the stamping formability of $\mathrm{CP} \mathrm{Ti}$ sheets at various temperatures. They found that springback could be reduced at elevated forming temperatures and drawing depth increased as the increase of forming temperature [3]. Zhang et al. studied the quasi-static tensile behaviors of large diameter thin-walled (LDTW) CP-Ti tube to get the fundamental understanding of bending formability with respect to temperature and strain

\footnotetext{
${ }^{a}$ Corresponding author: gliu@hit.edu.cn
}

This is an Open Access article distributed under the terms of the Creative Commons Attribution License 4.0, which permits unrestricted use, distribution, and reproduction in any medium, provided the original work is properly cited. 

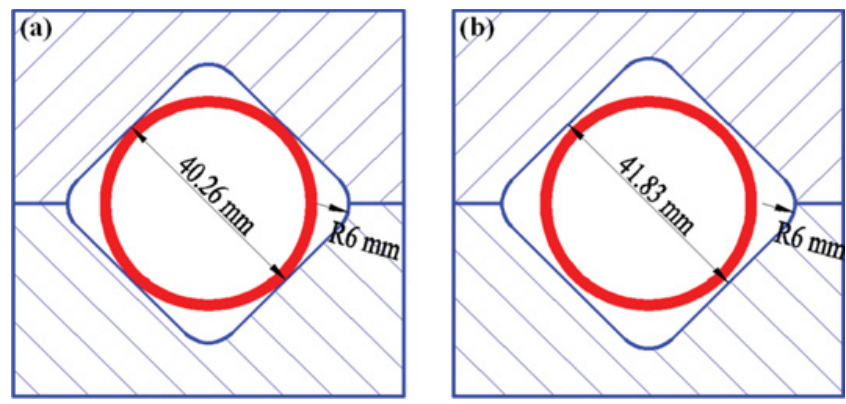

Figure 1. Round-to-square die set (a) expansion ratio of $20 \%$ and b) expansion ratio of $25 \%$ ).

rate [4]. According to hot sheet metal forming of Ti-6242, increasing forming temperatures alone would not necessarily imply better forming characteristics and optimal forming conditions would be a combination of forming velocity, temperature and holding time, as verified by Eva-Lis Odenberger et al. [2]. They also investigated the possibility to design suitable thermo-mechanical forming processes for titanium sheet metal component with acceptable accuracy, using finite element (FE) analyses of hot sheet metal forming in the titanium alloy Ti-6Al-4V [5, 6]. Nitin Kotkunde et al. performed deep drawing experiments of Ti-6Al-4V alloy sheet at elevated temperature and found that maximum LDR of 1.8 was achieved at $400^{\circ} \mathrm{C}$ but it was still lesser than other structural alloy [7]. Z. B. He et al. measured the formability of TA2 pure titanium at different temperature and determined the best forming parameters [8]. G. Liu et al. presented high pressure gas forming process based on QPF, HMGF and Hydroforming [9]. With the maximum pressure of $30 \mathrm{MPa}$, they also successfully formed Ti-alloy components with irregular cross section and square cross section at $850^{\circ} \mathrm{C}$ [10]. In this study, the high pressure gas forming process of Ti-alloy hollow part with square cross-section was developed further at higher pressure levels and lower temperatures. The flow stress behavior of Ti-3Al-2.5V tube was studied by uniaxial tension tests at elevated temperatures. The effects of pressurization path on the corner filling behavior and thickness distribution are discussed.

\section{Experimental details}

A high pressure gas forming (HPGF) device with maximum pressure of $70 \mathrm{MPa}$ developed by Harbin Institute of Technology was used to bulge the tubes inside the closed die in order to fill the die cavity. The round-to-square die set with two steps was designed and manufactured for the HPGF experiments, which is shown in Fig. 1. The die cavity has two square zones, a larger zone with expansion ratio of $25 \%$ and a smaller zone with expansion ratio of 20\%. Ti-3Al-2.5V (ASTM Gr. 9) titanium alloy seamless tubes, with $40 \mathrm{~mm}$ in outer diameter, $200 \mathrm{~mm}$ in length and $2 \mathrm{~mm}$ in thickness, were used in this study. The tensile tests were carried out on an Instron 1361 testing machine at two different temperatures $\left(650^{\circ} \mathrm{C}\right.$ and $\left.700{ }^{\circ} \mathrm{C}\right)$ and three nominal strain rates $\left(0.001 \mathrm{~s}^{-1}, 0.01 \mathrm{~s}^{-1}\right.$, and $\left.0.1 \mathrm{~s}^{-1}\right)$ to investigate the flow stress behavior of Ti-3Al-2.5V tube at elevated temperatures. HPGF experiments were also carried out with various pressurization paths and at the temperatures of $650{ }^{\circ} \mathrm{C}$ and $700^{\circ} \mathrm{C}$. Boron nitride was chosen as the lubricant during HPGF experiments. Meanwhile, a KEYENCE laser displacement sensor was used to measure the displacement of transition corner of the smaller zone with expansion ratio of $20 \%$ at the parting surface in real time. 


\section{ICNFT 2015}
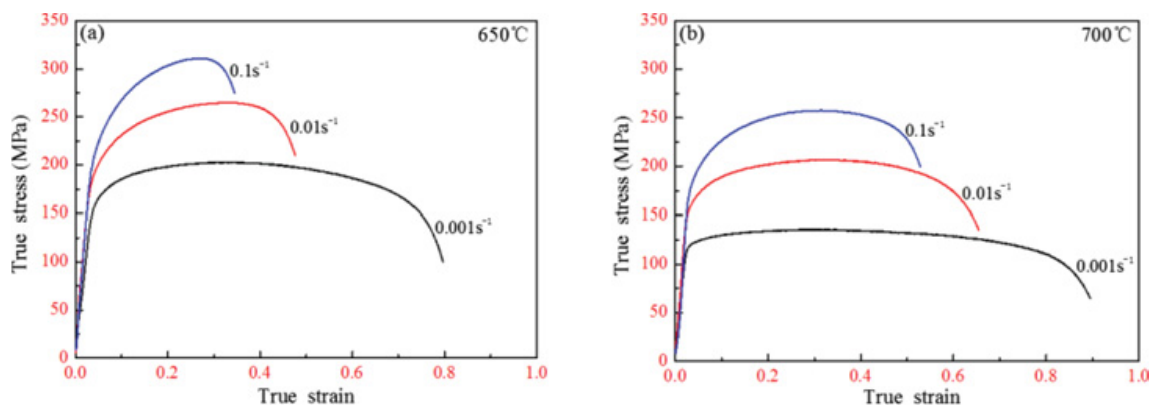

Figure 2. Flow curves of Ti-3Al-2.5V alloy tube tested at various temperatures and strain rates (a) $650{ }^{\circ} \mathrm{C}$ and b) $\left.700{ }^{\circ} \mathrm{C}\right)$.

\section{Results and discussion}

\subsection{Tensile test results}

Figure 2 shows the true stress-strain curves of Ti-3Al-2.5V alloy tube from the tensile tests at two different temperatures and three nominal strain rates. It can be seen that the flow stress decreases with increasing temperatures and decreasing strain rates. At the temperature of $650{ }^{\circ} \mathrm{C}$ and strain rate of $10^{-1} \mathrm{~s}^{-1}$, the flow curve exhibits the power-law constitutive relation obviously until peak stress is reached, at which level a softening region leading to fracture is observed [11]. Similar flow behavior is observed for the specimen tested at $700{ }^{\circ} \mathrm{C}$. The results indicate that dynamic recovery and dynamic recrystallization occured during testing. The flow behavior variations at different deformation conditions are probably related to the hardening and softening mechanisms $[11,12]$. The true strain is still above 0.3 even if the strain rate is up to $10^{-1} \mathrm{~s}^{-1}$ at $700^{\circ} \mathrm{C}$ and it is above 0.3 when the strain rate is $10^{-2} \mathrm{~s}^{-1}$ at $650{ }^{\circ} \mathrm{C}$, which indicates that it is suitable for the HPGF process of Ti-3Al-2.5V alloy tube at lower temperatures.

\subsection{The effect of pressurization path on corner filling process}

Figure 4(a) shows the corner filling behavior in the zone with expansion ratio of $20 \%$ of the components formed under two different pressurization paths and $650{ }^{\circ} \mathrm{C}$. The corresponding pressurization paths recorded during the HPGF process are shown in Fig. 4(b). It can be found that the tube burst with the pressurization path of $45 \mathrm{MPa}$. The fracture occurred in the straight wall area of the zone with expansion ratio of $25 \%$, as shown in Fig. 5. At the beginning of corner filling process, the strain rate was very high when the pressure level reached $45 \mathrm{MPa}$ and the low elongation at $650{ }^{\circ} \mathrm{C}$ resulted in fracture prematurely. This can be also proved in Fig. 3(a). With the pressurization path of 35-45 MPa, the strain rate dropped at the beginning of corner filling and the fracture was avoided. The successfully formed part is shown in Fig. 5(b).

Figure 6(a) shows the corner filling behavior in the zone with expansion ratio of $20 \%$ of the components formed under two different pressurization paths and $700{ }^{\circ} \mathrm{C}$. The corresponding pressurization paths recorded during the HPGF process are shown in Fig. 6(b). The part was fully formed with the pressurization path of $45 \mathrm{MPa}$ in $180 \mathrm{~s}$. This is because the elongation is improved with the increasing temperature. With the pressurization path of $25-35-45 \mathrm{MPa}$, the part was also fully formed in $300 \mathrm{~s}$. At elevated temperature and with constant pressure level of $45 \mathrm{MPa}$, the corner filling is slower as the radius gets smaller. This results from the strain rate sensitivity at elevated temperature. Compared with the pressurization path of $45 \mathrm{MPa}$, the total filling time is longer under the profile of 25-35-45 MPa, but the corner filling rate is kept in a certain range. It can be concluded that the optimized 


\section{MATEC Web of Conferences}
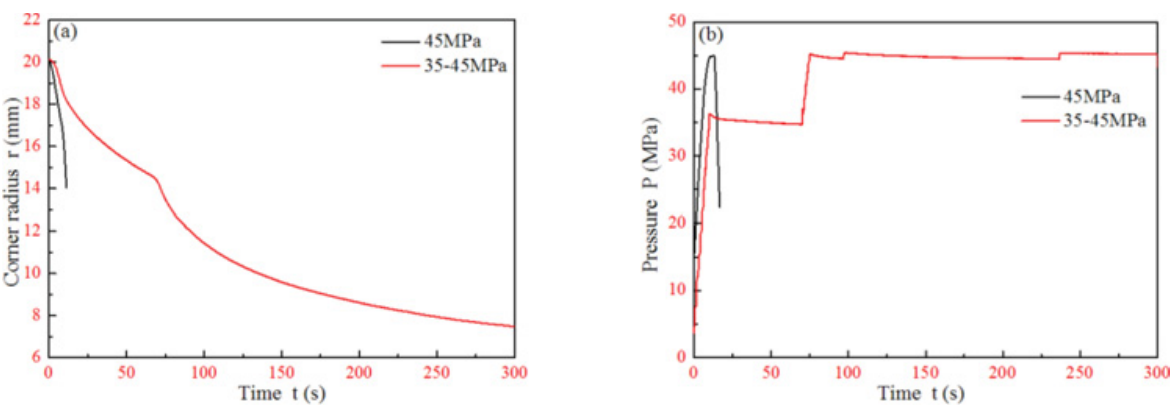

Figure 3. HPGF experiments at $650^{\circ} \mathrm{C}$ (a) corner filling curves and b) pressurization paths).
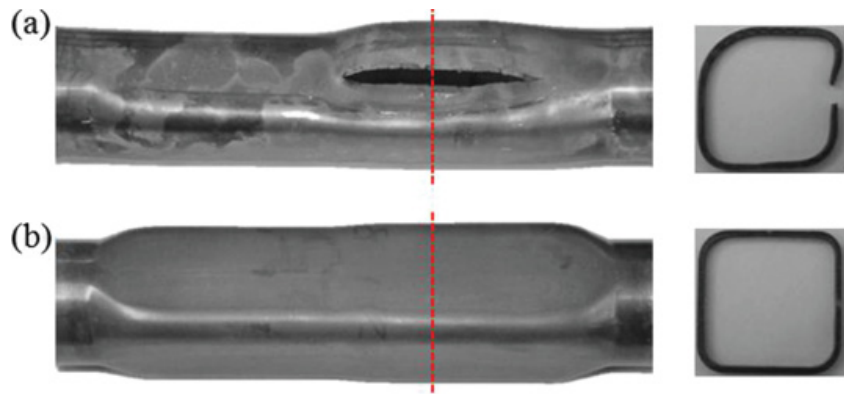

\section{$2 \underline{\mathbf{m m m}}$}

Figure 4. The tubular parts formed at $650{ }^{\circ} \mathrm{C}$ (a) pressurization path of $45 \mathrm{MPa}$ and b) pressurization path of $35-45 \mathrm{MPa})$.
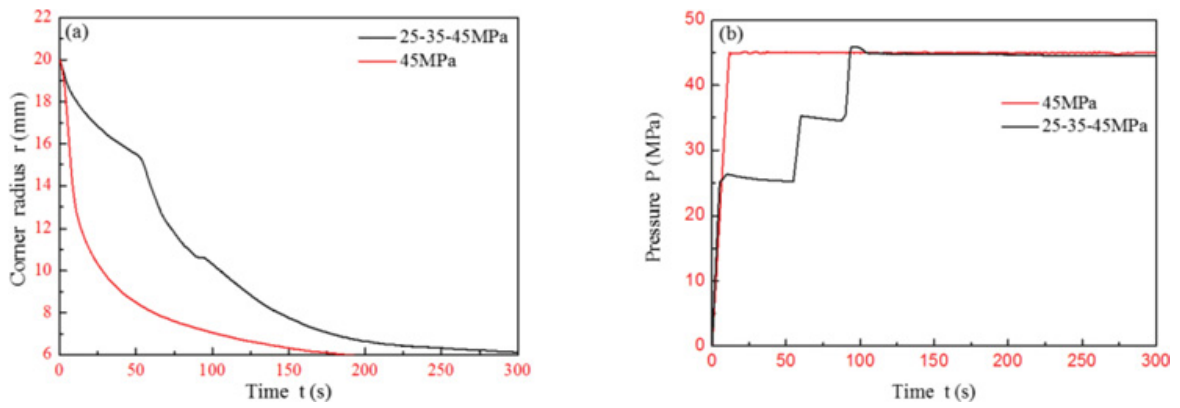

Figure 5. HPGF experiments at $700{ }^{\circ} \mathrm{C}$ (a) corner filling curves and b) pressurization paths).

pressurization path with increasing pressure level is an effective method to realize nearly constant filling rate in corner filling process.

\subsection{The effect of pressurization path on thickness distribution}

The thickness profiles in the zone with expansion ratio of $20 \%$ of the components formed under two different pressurization paths and $700{ }^{\circ} \mathrm{C}$ are also analyzed, as shown in Fig. 7. Considering the symmetry of die cavity with square cross-section, an eighth of the component was analyzed. It can be found obviously that deformation at the straight wall area is larger than that at the corner area. With 


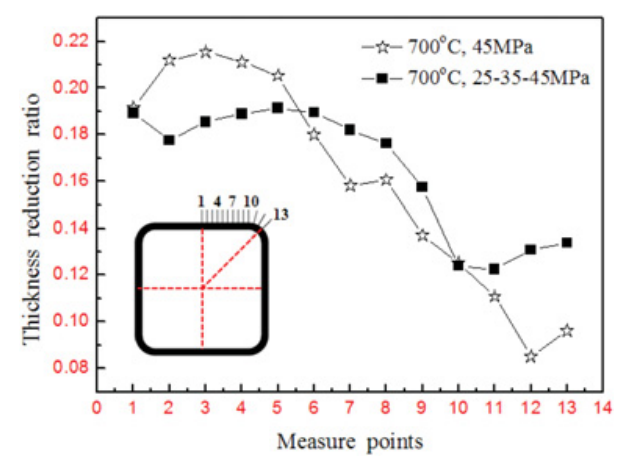

Figure 6. The thickness profiles under different pressurization paths.

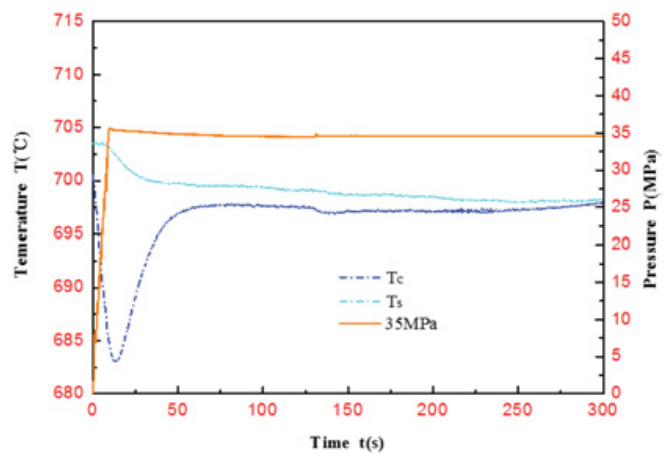

Figure 7. The temperature curves of two typical points under the pressurization path of $35 \mathrm{MPa}$.

the profile of $45 \mathrm{MPa}$, the maximum thinning ratio is $21.6 \%$ and it occurs close to the center of straight wall area. The minimum thinning ratio is $8.5 \%$ and it occurs close to the center of corner area. With the profile of 25-35-45 MPa, the thickness uniformity is improved to a certain degree. The maximum and minimum thinning ratio are $19.2 \%$ and $12.3 \%$ respectively. This is very different from hydroforming at room temperature, in which the maximum thinning ratio usually occurs at the transition area between the center of straight wall area and corner area. This case is also reflected in Fig. 5(a), where the fracture occurs at the middle area of straight wall. Besides, the lower strain rate and smaller friction force under the profile of 25-35-45 MPa could provide more uniform thickness profile.

During HPGF process in a square cross-sectional die, the tube comes into contact with the straight wall area of the die first and it comes into contact with the corner area last. The heating effect of the die and cooling effect of the inflowing gas with high pressure probably affect the temperature distribution of the tube and change the thickness profile of the formed component further. In view of this speculation, the temperatures of two typical points on the tubular component was measured and recorded by using two $\mathrm{K}$ type thermocouples and a data acquisition module, viz. temperature at the center of straight wall area $\left(\mathrm{T}_{s}\right)$ and temperature at the center of corner area $\left(\mathrm{T}_{c}\right)$. During the HPGF process at $700{ }^{\circ} \mathrm{C}$, the temperatures at the two points and the corresponding pressurization path were recorded, as shown in Fig. 7. When the gas flowed into the tube with the pressurization path of $35 \mathrm{MPa}, \mathrm{T}_{c}$ descended from $700{ }^{\circ} \mathrm{C}$ greatly, but $\mathrm{T}_{s}$ just descended a little. Because of the direct contact with the straight wall center of die cavity at the beginning, the strong heat conduction at the center of tube's straight wall area counteracted the cooling effect of inflowing gas. For the center of tube's corner area, however, the heat conduction was not strong enough without the direct contact with the die, and the cooling 


\section{MATEC Web of Conferences}

effect was obvious. Temperature difference between the center of the straight wall area and the corner area occurred, and the maximum value could reach $19{ }^{\circ} \mathrm{C}$. As a result, deformation at the straight wall area was larger than that at the corner area during the non-isothermal stage, which resulted in special thickness profile of the formed component. In the future, more experiments will be done to explore how to reduce the temperature difference and improve the thickness profile.

\section{Conclusion}

In the present work, high pressure gas forming and flow behavior of Ti-3Al-2.5 V titanium tubes at elevated temperatures have been investigated, conclusions can be drawn from this work as follows:

At the temperature of $650^{\circ} \mathrm{C}$ and $700{ }^{\circ} \mathrm{C}$, the flow curves exhibit the power-law constitutive relation until peak stress is reached, at which level a softening region leading to fracture is observed.

Compared to the pressurization path with constant pressure level, the stepped pressurization path is effective to avoid the premature fracture and realize nearly constant filling rate in corner filling process.

After HPGF in a square cross-sectional die, the thickness profiles are very different from that in conventional hydroforming: deformation at the straight wall area is larger than that at the corner area and the maximum thinning ratio occurs close to the center of straight wall area. Temperature difference between the center of the straight wall area and the corner area occurs during the inflow process and it results in special thickness profile. Besides, because of lower strain rate and smaller friction force, the stepped pressurization path can provide more uniform thickness profile.

This work was financially supported by Program for Changjiang Scholars and Innovative Research Team in University (No. IRT1229).

\section{References}

[1] C. Leyens, M. Peters, Titanium and titanium alloys (Wiley-VCH, Weinheim, 2003)

[2] E-L. Odenberger, R. Pederson, M. Oldenburg, Mater. Sci. Eng. A, 489, 158-168 (2008)

[3] F-H. Chen, K-H. Chiu, J. Mater. Proc. Tech, 170, 181-186 (2005)

[4] Z.Y. Zhang, H. Yang, H. Li, N. Ren, D. Wang, Mater. Sci. Eng. A, 569, 96-105 (2013)

[5] E-L. Odenberger, M. Oldenburg, P. Thilderkvist, T. Stoehr, J. Lechler, M. Merklein, J. Mater. Proc. Tech, 211, 1324-1335 (2011)

[6] E-L. Odenberger, J. Hertzman, P. Thilderkvist, M. Merklein, A. Kuppert, T. Stöhr, J. Lechler, M. Oldenburg, Int. J. Mater. Form, DOI 10.1007/s12289-012-1093-8 (2012)

[7] N. Kotkunde, A.D. Deole, A.K. Gupta, S.K. Singh, B. Aditya, Mater Design, 60, 540-547 (2014)

[8] Z.B. He, B.G. Teng, Trans. Nonferrous. Met. Soc. China, 22, 479-484 (2012)

[9] G. Liu, K.H. Wang, Y. Xu, B. Wang, S.J. Yuan, Adv. Mater. Res, 712, 651-657 (2013)

[10] G. Liu, J.L. Wang, K.X. Dang, Z.J. Tang, Mater, 7, 5992-6009 (2014)

[11] H.Y. Wu, W.C. Hsu, J Alloys Compd, 493, 590-594 (2010)

[12] L.C. Tsao, H.Y. Wu, J.C. Leong, C.J. Fang, Mater Design, 34, 179-184 (2012) 